Bangladesh J. Plant Taxon. 23(2): 199-207, 2016 (December)

(C) 2016 Bangladesh Association of Plant Taxonomists

\title{
NUMERICAL TAXONOMIC ANALYSIS IN LEAF ARCHITECTURAL TRAITS OF SOME HOYA R. BR. SPECIES (APOCYNACEAE) FROM PHILIPPINES
}

\author{
Jess H. Jumawan ${ }^{1}$ And Inocencio E. Buot, JR \\ Institute of Biological Sciences, University of the Philippines, Los Bańos, College, \\ Laguna, Philippines
}

Keywords: Cluster Analysis; Multivariate Analysis; Numerical Taxonomy; Principal Coordinate Analysis.

\begin{abstract}
The present study examines the leaf variations in leaf traits of four Hoya R. Br. species from Philippines namely: (1) H. buotii Kloppenburg, (2) H. halconensis Kloppenburg, (3) H. mindorensis Schlechter red bearing flowers; and (4) H. mindorensis Schlechter yellow bearing flowers. Leaf samples ( $n=30$ leaves) were collected from each plant group and measured with nine architectural traits. The results showed variability in the leaves using univariate and multivariate analysis. Data ordination depicted variations in leaf morphology. The two plant groups $H$. mindorensis red bearing flowers and $H$. mindorensis yellow bearing flowers were consistently variable as supported by principal coordinate analysis, cluster analysis and two way Anova $(\mathrm{P}<0.001)$. The variability of the two plant groups could be due to developmental instability, plasticity or taxonomic identity, one being the subspecies of the other. Hence, a closer study to investigate the significant variability of the two plant groups was recommended. Distinct separation of $H$. buotii and $H$. halconensis was detected being regularly mistaken as one species. The study demonstrated the applicability of multivariate analysis as effective tool in numerical taxonomy. Multivariate analysis can be employed to demonstrate likelihood of relationship among various Hoya species.
\end{abstract}

\section{Introduction}

Most Hoya species of Philippines were considered endemic to the country with several new discoveries for the past decade. The genus Hoya, is commonly known as wax plant belong to family Apocynaceae, was considered to be taxonomically complex (Wanntorp et al., 2006). The estimated number of Hoya species in the country ranges from 80 - 104 (Kloppenburg et al., 2012 and Aurigue et al., 2013). The Philippines was considered as one of the richest and most diverse range of Hoya species which are located all throughout the archipelago (Kloppenburg and Siar, 2008).

Identification of Hoya species largely depend on traditional taxonomy that put emphasis on reproductive characters. Descriptions on qualitative and quantitative characteristics of inflorescence, corolla, corona and pollinarium were very significant in identification of Hoya species (Kleijn and Van Donkelaar, 2001; Omlor, 1996; Forster and Little, 1996). Nomenclature issues were still largely unresolved for various taxa (Rodda and Juhoneweb, 2013). Many species were documented to exhibit phenotypic plasticity in morphological characters (Tungmunnithum et al., 2011). The structure of many Hoya species was described to possess complex corona morphology (Kunze, 2008). Many of these problems in Hoya taxonomy had risen due to dependence on reproductive parts. Reproductive features are not present all the time and makes difficulty in identification.

\footnotetext{
${ }^{1}$ Corresponding author. Email: jehoju@gmail.com
} 
DNA barcode was the method suggested to properly identify the endemic Philippine Hoya species (Maranan and Diaz, 2013). The technique was regarded as an effective tool for species identification but considerably weak attempt to discovery and description of species (Wheeler, 2004). Aside from being an expensive method for species identification, DNA barcoding is insufficient in terms of theoretical basis of traditional taxonomy (Lipscomb et al., 2003).

Leaves of Philippine Hoya species are present throughout the year and can be used extensively for detecting variations. Leaf characters were proven to be valuable in taxonomic studies of tropical plants which seldom produce flowers and angiosperm remains as fossils (Hickey and Taylor, 1991; Dilcher, 1974). Leaf morphological characters of Gunneraceae were subjected to multivariate analysis to support genus monophyly (Fuller, 2005). Leaf morphometric data are important and the variation displayed by morphological traits reflects the evolutionary arrangement manifested as morphological changes (Otte and Endler, 1989). Multivariate analysis is a tool in the examination of leaf morphometric traits, an important component in the field of numerical taxonomy. The main objective of the study was to examine the variations of the leaf morphometric traits of the selected Hoya species namely: Hoya buotii, Hoya halconensis, and Hoya mindorensis.

\section{Materials and Methods}

Plant materials

The Hoya species were acquired from the propagated plant collections of Dr. I. E. Buot Jr., Professor and curator of IBS Herbarium, PBD in UPLB. There were 3 species of Hoya included in the study which were Hoya buotii, Hoya halconensis, and Hoya mindorensis. However, it was noticed that $H$. mindorensis bears two flower types: the red bearing plants and the yellow bearing plant. For the purpose of this examination, the analyses were conducted in four plant groups: (1) $H$. buotii, (2) H. halconensis (3) H. mindorensis red bearing flowers; and (4) H. mindorensis yellow bearing flowers. The selected Hoya species usually encountered confusion in proper taxonomic identification.

\section{Leaf character selection and measurements}

The selection of leaf morphometric characters were based from manual of leaf architecture with modifications (Leaf Architecture Working Group, 1999). A total of nine morphometric traits were chosen in the study. The description and illustration of the parameters considered for leaf morphometric measurements were shown in Table 1 and Fig. 1.

Table 1. Parameters of leaf morphometric measurements used in the analysis.

\begin{tabular}{ll}
\hline Code & Description of characters \\
\hline LL & Lamina length \\
LW & Lamina width \\
PW & Petiole width \\
WL & Width in left side of lamina \\
WR & Width in right side of lamina \\
VL & Number of secondary veins in left side of the lamina \\
VR & Number of secondary veins in right side of the lamina \\
LR & Leaf ratio (LL/LW) \\
LA & Leaf area (LL X LW X 2/3) \\
\hline
\end{tabular}




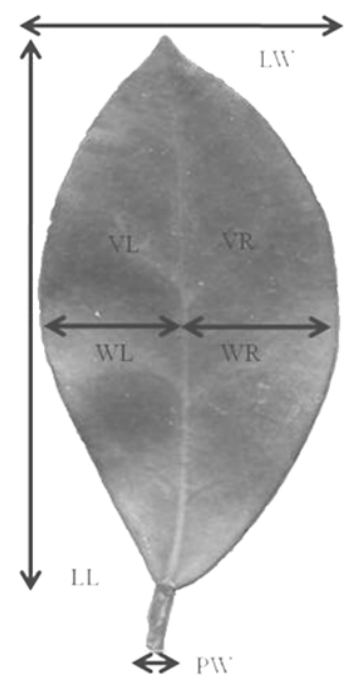

Fig. 1. The illustration of the parameters taken for leaf morphometric measurements.

\section{Data analysis}

There were four plant groups, nine leaf morphometric data, and thirty leaf sample replicates which has a total of 1,080 data sets. The data generated from the leaf morphometric traits were subjected to univariate and multivariate statistical analyses. The univariate data comprised the minimum value, maximum value, mean and standard deviation. The univariate data sets were plotted in a box and whisker to evaluate the distribution of data. The multivariate data matrix was subjected to similarity matrix using Morisita index of similarity. The similarity matrix was explored using data ordination technique. Ordination refers to projection of multivariate data sets in a two dimensional space to detect patterns upon visual inspection (Pielou, 1984). Principal coordinate analysis (PCOa) or also known as metric multidimensional scaling was implemented as data ordination (Gower, 1966). PCOa reduces the dimensionality of the data similar to principal component analysis but the advantage of PCoA is that it may be used with all types of variables (Legendre and Legendre, 1998). Cluster analysis was performed combining quantitative data into clusters in constructing a dendrogram. The resulting pattern generated from multivariate analysis detected variations in leaf morphometric traits. An inference on the sources of leaf morphometric variation was tested using two way analysis of variance (Anova). It was investigated if the significant variation could be attributed by the leaf characters, the species, and the interaction of leaf characters and species. Post hoc analysis was conducted when $\mathrm{P}<0.05$ using Tukey's test. The PAST (Paleontological Statistical Software) software (Hammer et al., 2009) was used in analyzing univariate and multivariate analysis.

\section{Results}

The univariate statistics of the morphometric traits of the plant groups are shown in Table 2 and Fig. 2. The results indicated that the leaf area and leaf length were the most variable among the measured leaf characters. The least variable traits were petiole width and leaf ratio. The rest of the leaf traits were relatively similar to the four plant groups. 


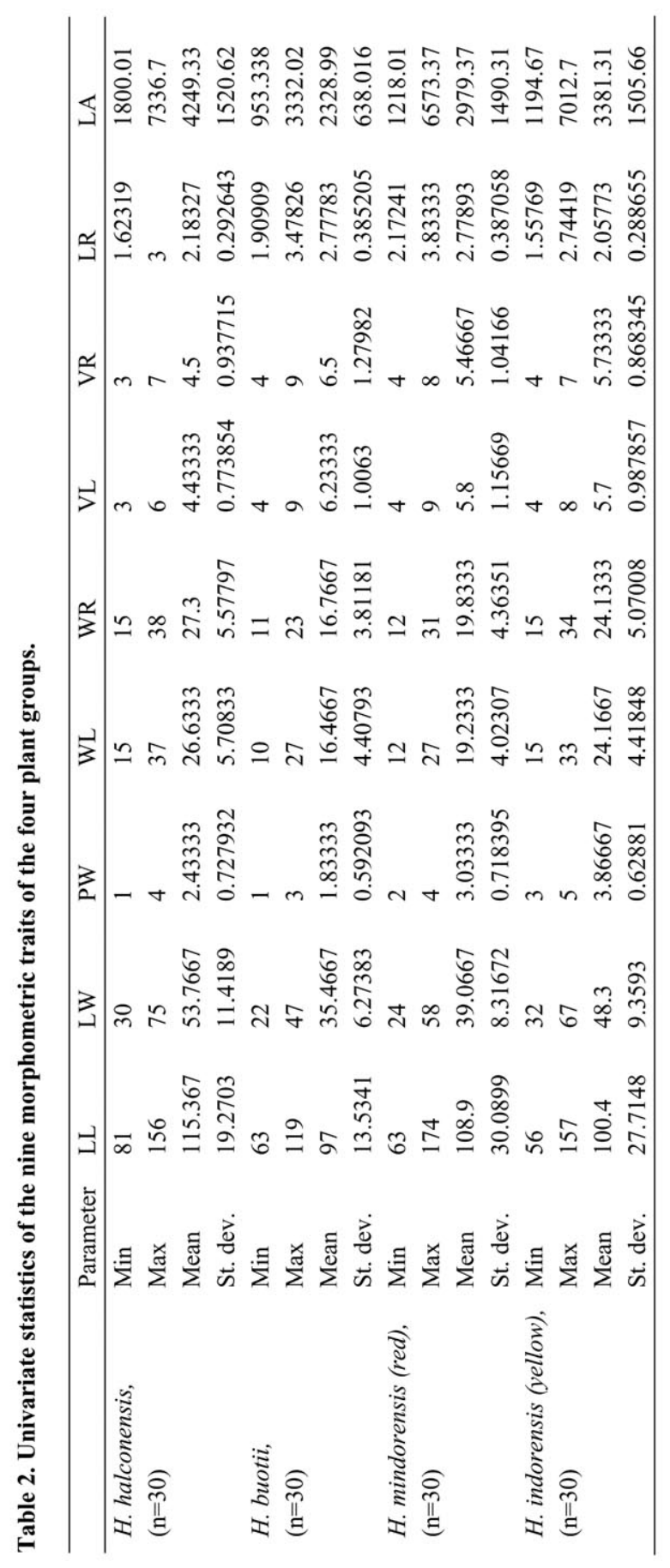




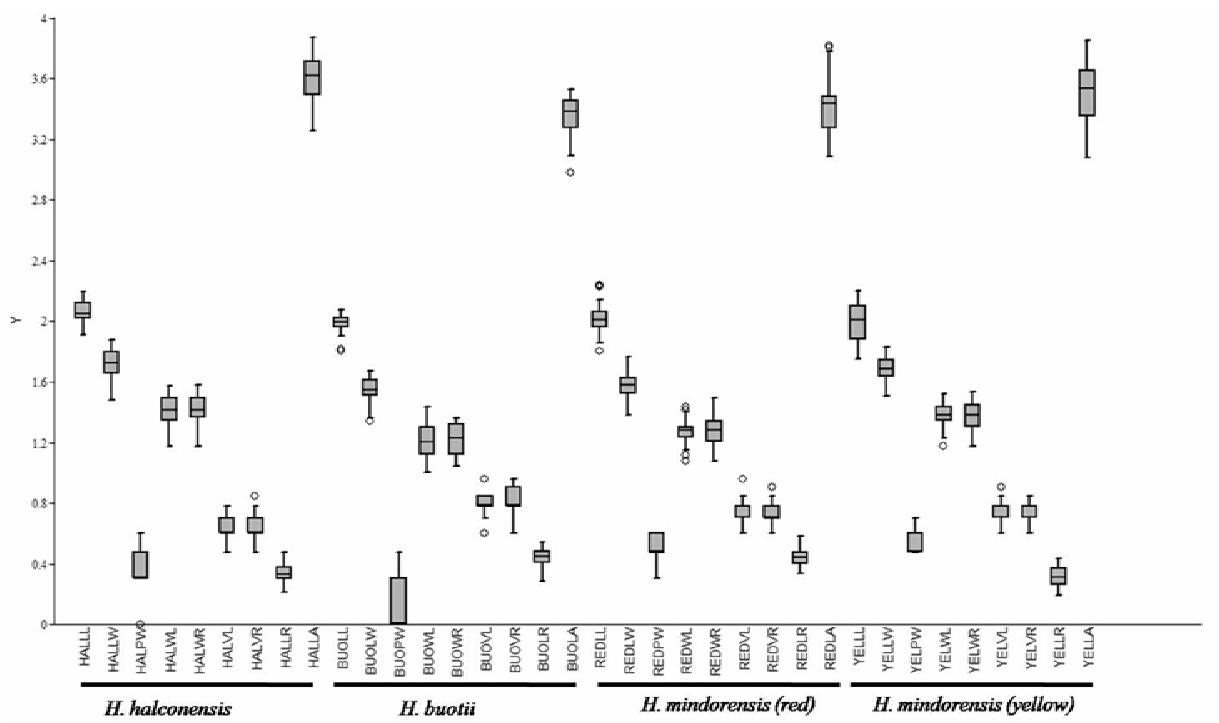

Fig. 2. Box and whisker plot on the univariate metrics of leaf morphometric traits of the four plant groups.

The results in PCOa accounted 4 effective coordinate axis with a total of $68.09 \%$ of the cumulative variance (Table 3). Axis 1 and axis 2 contributed $36.30 \%$ and $59.02 \%$ of variances respectively. The components in axis 1 and axis 2 were analyzed and used to project into a two dimensional plane (Table 4 and Fig. 3). The highest values generated in axis 1 and axis 2 was largely attributed to the leaf morphometric traits of $H$. mindorensis red bearing plant. The lowest values on the other hand were attributed to leaf traits of $H$. mindorensis yellow bearing plant. It can be viewed that leaf traits of the two $H$. mindorensis plants were highly variable. The leaf traits from $H$. buotii and $H$. halconensis were less variable.

Table 3. The eigenvalue of the principal coordinate axis and the respective accounted variance in the PCOa.

\begin{tabular}{llll}
\hline Axis & Eigenvalue & Percent variance & Cumulative variance \\
\hline 1 & 0.033984 & 36.301 & 36.301 \\
2 & 0.021271 & 22.721 & 59.022 \\
3 & 0.0047677 & 5.0928 & 64.1148 \\
4 & 0.003722 & 3.9759 & 68.0907 \\
\hline
\end{tabular}

The data ordination of PCOa clearly displayed the variation of the leaf morphometric traits between the two $H$. mindorensis plant groups (Fig. 3). The red bearing flower $H$. mindorensis occupied quadrant 1 and quadrant four of the orthogonal plane. The yellow bearing flower $H$. mindorensis largely occupied quadrant 2. The rest of the values were distributed closely in quadrants 3 and 4.

Another technique employed in the exploratory analysis of the morphometric data was cluster analysis. The dendrogram also revealed a similar pattern observed in PCOa. Again, the two $H$. mindorensis plant groups were located on the opposite ends of the dendrogram. It indicated that the two plant groups were highly variable. The $H$. mindorensis yellow bearing flower was more 
morphometrically similar $H$. buotii but their Euclidean distance was still far. This indicated variability of leaf morphometric traits. The $H$. mindorensis red bearing flower was very similar to $H$. halconensis in terms of the measured leaf traits. In general, the four plant groups revealed distinct leaf characteristics as indicated by the clusters in the dendrogram (Fig. 4).

Table 4. The principal coordinate scores of the two highest accounted variances in axis1 and axis 2 on the nine morphometric traits derived from the four plant groups. (Legend: The first three letters comprise the plant groups as HAL $=H$. halconensis ; $\mathrm{BUO}=H$. buotii; $\mathrm{RED}=H$. mindorensis (red); and YEL $=H$. mindorensis (yellow). The last two letters comprise the code characters of the leaf in Table 1).

\begin{tabular}{|c|c|c|c|c|c|}
\hline Leaf traits & axis 1 & axis 2 & Leaf traits & axis 1 & axis 2 \\
\hline REDLA & 0.1130 & 0.0470 & BUOLL & -0.0025 & -0.0007 \\
\hline REDLL & 0.0374 & 0.0153 & HALWL & -0.0059 & -0.0333 \\
\hline BUOPW & 0.0336 & 0.0051 & YELVR & -0.0068 & 0.0120 \\
\hline REDWR & 0.0296 & 0.0097 & HALWR & -0.0083 & -0.0357 \\
\hline REDPW & 0.0294 & -0.0007 & HALLR & -0.0085 & 0.0114 \\
\hline REDLW & 0.0287 & 0.0102 & HALLW & -0.0092 & -0.0361 \\
\hline REDWL & 0.0281 & 0.0107 & HALLL & -0.0101 & -0.0223 \\
\hline BUOWR & 0.0167 & -0.0050 & YELVL & -0.0112 & 0.0137 \\
\hline HALPW & 0.0166 & -0.0258 & YELLR & -0.0141 & 0.0086 \\
\hline BUOWL & 0.0138 & -0.0076 & BUOLR & -0.0177 & -0.0064 \\
\hline BUOLA & 0.0101 & -0.0027 & HALLA & -0.0206 & -0.0796 \\
\hline REDVR & 0.0082 & -0.0100 & YELWL & -0.0244 & 0.0156 \\
\hline REDVL & 0.0077 & -0.0126 & HALVR & -0.0248 & -0.0034 \\
\hline BUOLW & 0.0065 & 0.0001 & YELPW & -0.0276 & 0.0078 \\
\hline REDLR & 0.0020 & 0.0025 & YELLW & -0.0279 & 0.0154 \\
\hline BUOVL & 0.0001 & -0.0040 & YELWR & -0.0321 & 0.0154 \\
\hline HALVL & -0.0018 & -0.0019 & YELLL & -0.0385 & 0.0268 \\
\hline BUOVR & -0.0024 & -0.0087 & YELLA & -0.0869 & 0.0691 \\
\hline
\end{tabular}

The emerging pattern generated in data exploration using multivariate analysis suggested variability and resemblances on the leaf morphometric traits. To detect if the variation was significant or not, two way Anova was conducted. The sources of variation were generated from the leaf characters, four plant groups and the interaction between leaf characters and four plant groups. The two way Anova detected a highly significant differences among the mentioned sources of variation. Post hoc analysis was conducted using Tukey's test in the four plant groups only. It was not conducted to the leaf characters as it may give irrelevant output (e.g. leaf area is obviously significantly different to petiole width). The Tukey's test revealed that $H$. halconensis and $H$. mindorensis red bearing flower were more similar compared to other comparison. The $H$. mindorensis red bearing flower and $H$. mindorensis yellow bearing flower was highly significantly different. Other combinations of plant group comparisons showed highly significant differences in their leaf morphometric traits. The summary on the two way Anova table was shown in Table 5 and 6. 


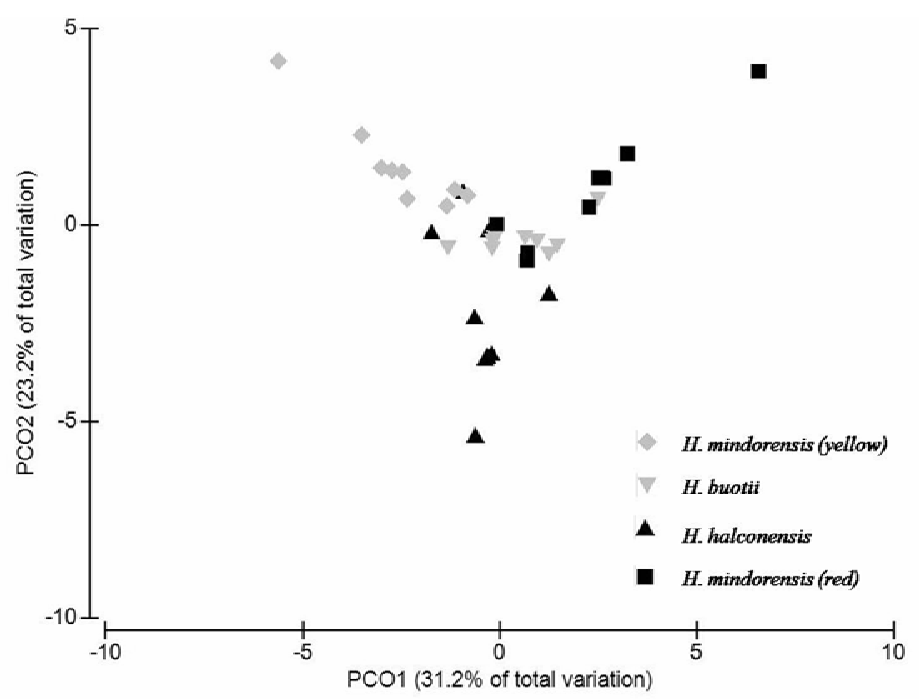

Fig. 3. The data ordination on the nine morphometric traits contributed by the four plant groups using PCOa.

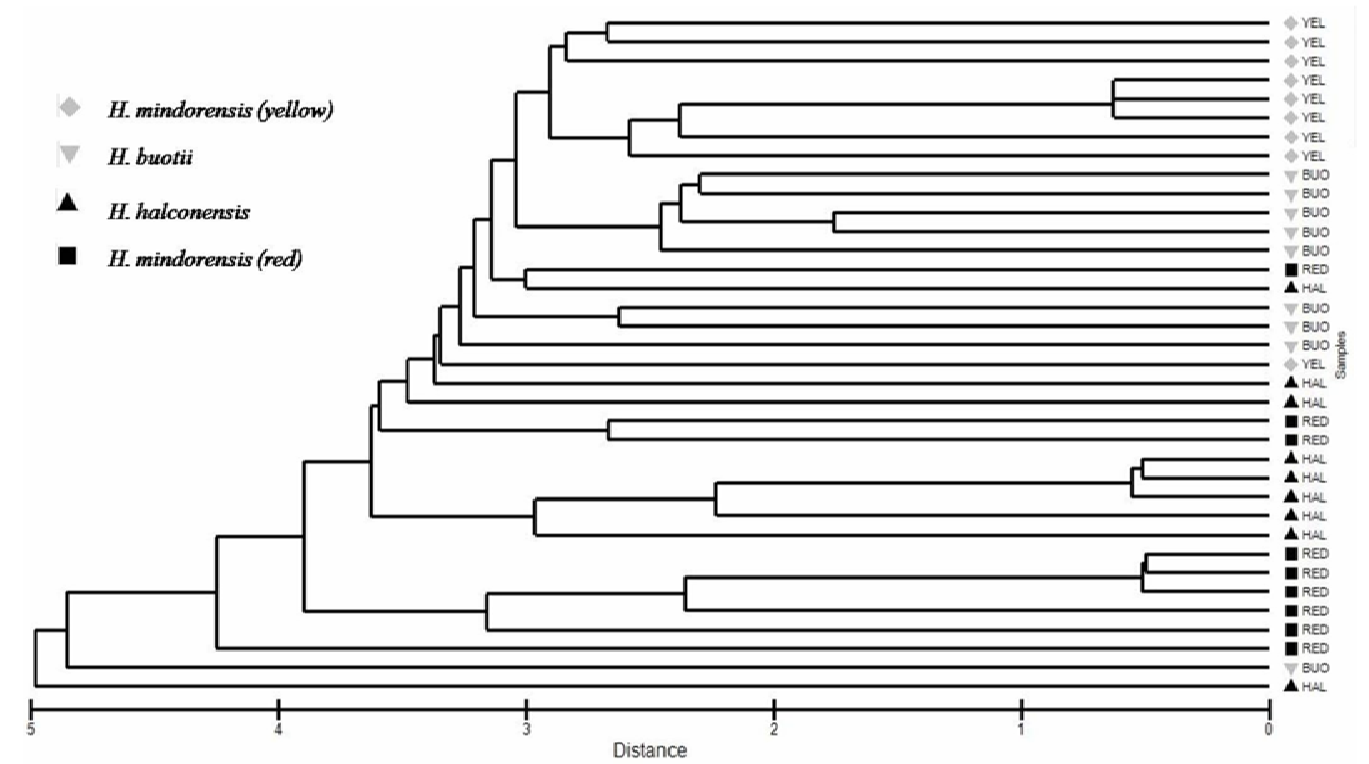

Fig. 4. Single linkage or nearest neighbor cluster dendrogram on the nine morphmetric traits from the leaves of the four plant groups.

Table 5. Two way Anova table on the sources of variation in leaf morphometric traits.

\begin{tabular}{llllll}
\hline Source & Sum of squares & df & Mean squares & F ratio & P value \\
\hline Leaf characters (A) & 985.8 & 8 & 123.2 & $\mathrm{~F}(8,232)=2530$ & $\mathrm{P}<0.0001$ \\
Species (B) & 9.887 & 3 & 3.296 & $\mathrm{~F}(3,87)=25.86$ & $\mathrm{P}<0.0001$ \\
Interaction: A x B & 62.51 & 24 & 2.605 & $\mathrm{~F}(24,696)=52.17$ & $\mathrm{P}<0.0001$ \\
Residual & 34.75 & 696 & 0.04993 & & \\
\hline
\end{tabular}


Table 6. Pair wise comparison on the different plant groups using Tukey's test.

\begin{tabular}{llll}
\hline Multiple Comparisons Test & Mean diff. & 95\% CI of diff. & Summary \\
\hline H. halconensis vs. H. buotii & 0.1244 & 0.04389 to 0.2048 & $* * *$ \\
H. halconensis vs. H. mindorensis (red) & -0.0312 & -0.1116 to 0.04931 & ns \\
H. halconensis vs. H. mindorensis (yellow) & -0.1443 & -0.2248 to -0.06386 & $* * * *$ \\
H. buotii vs. H. mindorensis (red) & -0.1555 & -0.2360 to -0.07506 & $* * * *$ \\
H. buotii vs. H. mindorensis (yellow) & -0.2687 & -0.3492 to -0.1882 & $* * * *$ \\
H. mindorensis (red) vs. H. mindorensis (yellow) & -0.1132 & -0.1936 to -0.03269 & $* *$ \\
\hline
\end{tabular}

\section{Discussion}

The study was conducted to examine the variations of the leaf morphometric traits of the four plant groups consisting Hoya species. The univariate statistical analysis showed pronounced variability in leaf area and laminar length. On the other hand, less variability was observed in petiole width and leaf ratio. Leaf variation was more conspicuous to parts of the leaf with bigger morphometric values. The multivariate analysis generated a pattern that the $H$. mindorensis red bearing flower and $H$. mindorensis yellow bearing flower were highly variable. This was supported by results on cluster analysis and the comparison using Tukey's test as post hoc analysis to two way Anova. The detected variability of the two plant groups, although belonging to the same species could be attributed to environmental stress (Van Valen, 1962). The effects of environmental stress can eventually lead to developmental instability manifested in variability of leaf traits (Valentine and Soule, 1973). Hoya species were known also to exhibit phenotypic plasticity (Tungmunnithum et al., 2011). Leaf variations of the two plant groups could be phenotypic variation attributed to plasticity. On the other hand, a closer investigation should be conducted to consider other leaf parameters or another vegetative part of the plant. The variation of leaf traits between the two plant groups was highly significant, as also indicated by difference in the colour of the flowers. The possibility that they were taxonomically different, as a subspecies probably is at large. Hence, it is recommended that a separate study should be conducted that would incorporate many characters in the analysis.

In general, the multivariate analysis was able to detect variations of the morphometric traits on the leaves of selected Philippine Hoya species. The detected variation was statistically tested to discriminate one plant group to another. This study confirms the distinct separation of Hoya buotii and Hoya halconensis that had been always mistaken to be one species (Aurigue, 2013). This study demonstrated the applicability of multivariate analysis as a tool in numerical taxonomy. The technique detected variations in leaf morphometric traits and can further be employed to demonstrate likelihood of relationship among the Hoya species.

\section{Acknowledgement}

The authors would like to thank the Philippine government agency DOST-ASTHRDP for the support in the conduct of the study.

\section{References}

Aurigue, F.B. 2013. A collection of Philippine Hoyas and their culture. Philippine Council for Agriculture, Aquatic and Natural Resources and Development DOST, Laguna, Philippines 195p.

Aurigue, F.B., Sahagun, J. R., and Suarez, W. M. 2013. Hoya cutis-porcelana (Apocynaceae): A New Species from Samar and Biliran Islands, Philippines. Journal of Nature Studies. 12(1): 12-17

Dilcher, D.L.1974. Approaches to the identification of angiosperm leaf remains. Bot. Rev. 40: 1-156. 
Forster, P.I. and Little, D. J. 1996. Flora of Australia. 28: 231-237. CSIRO, Canberra.

Fuller, D.Q. 2005. Systematics and leaf architecture of the Gunneraceae. The Botanical Review 71(3): 295353.

Gower, J.C. 1966. Some distance properties of latent root and vector methods used in multivariate analysis. Biometrika 53: 325-338.

Hammer, O., Harper, D.A.T., and Ryan, P.D. 2009. Past version 1.91: Paleontological Statistical Software package for education and data analysis. Paleontologia Electronica 4 (1):9- 4.

Hickey, L.J. and Taylor, D.W. 1991. The leaf architecture of Ticodendron and application of foliar characters in discerning its relationships. Ann. Missouri. Bot. Gard., 78: 105-130.

Kleijn, D. and Van Donkelaar, R. 2001. Notes on the taxonomy and ecology of the genus Hoya (Asclepiadaceae) in Central Sulawesi. Blumea 46: 457-483.

Kloppenburg, R.D., Guevarra, M.L.D., Carandang, J.M. and Maranan, F.S. 2012. New Species of Hoya R. Br. (Apocynaceae) from the Philippines. Journal of Nature Studies 11(1\&2): 34-48.

Kloppenburg, R.D. and Siar S.V. 2008. Three new species of Hoya R.Br. (Apocynaceae) from the Philippines. Asia Life Sciences 17(1):57-70.

Kunze, H. and Wanntorp, L. 2008. Corona and anther skirt in Hoya (Apocynaceae, Marsdenieae). Plant Syst. Evol. 271: 9-17.

Legendre, P. and Legendre, L. 1998. Numerical Ecology. 2nd English edition. Elsevier, Amsterdam.

Lipscomb, D., Platnick, N. and Wheeler, Q.D. 2003. The Intellectual Content of Taxonomy: A Comment on DNA Taxonomy. Trends in Ecology and Evolution 18(2): 65-66.

Leaf Architecture Working Group. 1999. Manual of Leaf Architecture - morphological description and categorization of dicotyledonous and net-veined monocotyledonous angiosperms. Washington, DC.

Maranan, F.S. and Diaz, M.G.Q. 2013. Molecular Diversity and DNA Barcode Identification of Selected Philippine Endemic Hoya Species (Apocynaceae). The Philippine Agricultural Scientist 96 (1): 86-92.

Omlor, R. 1996. Notes on Marsdenieae (Asclepiadaceae) - A new, unusual species of Hoya from northern Borneo. Novon 6: 288-294.

Otte, D. and Endler, J.A. 1989. Speciation and its consequences. Sunderland, Massachusetts. Sinauer Associates, pp 28-59.

Pielou, E. C. 1984. The interpretation of ecological data: A primer on classification and ordination. Wiley, New York.

Rodda, M. and Juhoneweb, N. S. 2013. The taxonomy of Hoya micrantha and Hoya revoluta (Apocynaceae, Asclepiadoideae). Webbia: Journal of Plant Taxonomy and Geography 68: (1) 7-16.

Tungmunnithum, D., Kidyoo, M. and Khunwasi, C. 2011. Morphological variations in Hoya siamica Craib (Asclepiadaceae) in Thailand. Tropical Natural History 11(1): 29-37.

Valentine, D.W., and Soule, M. 1973. Effect of p,p'-DDT on developmental stability of pectoral fin rays in the Grunion, Leuresthes tenuis. Fisheries Bulletin 71: 921-926.

Van Valen, L. 1962. A study of fluctuating asymmetry. Evolution 16: 125-142.

Wanntorp, L., Kocyan, A. and Renner, S.S. 2006. Wax plants disentangled: A phylogeny of Hoya (Marsdenieae, Apocynaceae) inferred from nuclear and chloroplast DNA sequences. Molecular Phylogenetics and Evolution 39: 722-733.

Wheeler, Q.D. 2004. Taxonomic triage and the poverty of phylogeny. Philosophical Transactions of the Royal Society of London, B 359: 571-583. 